NASZA DERMATOLOGIA Online OUR DERMATOLOGY Online

Source of Support: Nil

Competing Interests: None

\section{A STUDY OF CLINICAL AND BIOCHEMICAL CORRELATION IN PATIENTS OF PSORIASIS IN ACUTE EXACERBATION}

\author{
Neerja Puri, B B Mahajan \\ Department of Dermatology and Venereology, Punjab Health Systems Corporation, \\ Ferozepur, Punjab, India
}

Corresponding author: Dr. Neerja Puri

\begin{abstract}
Introduction: Psoriasis is a genetically determined chronic disease of skin in which a number of biochemical alterations take place during its course. The main objectives of our study were to calculate various biochemical parameters in psoriasis correlate them clinically.

Materials and Methods: An attempt was made to detect the biochemical changes during its exacerbations. Fifty biopsy proved psoriasis patients were selected. Clinical examination and the various biochemical tests were performed at the time of enrollment and at the end of eight weeks of treatment.

Results: Hyperurecemia was seen in $16 \%$ patients and hypocalcemia was seen in $10 \%$ patients and hypoalbuminaemia was seen in $56 \%$ patients.
\end{abstract}

Conclusion: With improvement of clinical picture, a shift of biochemical values towards normal was recorded.

Key words: Psoriasis; biochemical; PASI score; hypoalbuminaemia; hyperuricaemia; hypocalcaemia

\section{Introduction}

Psoriasis is a chronic recurrent papulosquamous disorder characterized by epidermal hyperplasia [1]. There is, increased mitotic activity of the basal cell layer which results in rapid epidermal cell turnover with the 28 day normal epidermal cell cycle reduced to 5 days. The stimulus for the increased rate of keratinization and even the site of the initial pathologic changes remains controversial [2].

Psoriasis even today continues to be a , great dermatologic mystery.' Controversy exists regarding the mechanism underlying the rapidly increased epidermal turnover [3]. In any event, the six to nine fold transit time increase does not allow the normal events of cell maturation and keratinization to take place. This is reflected clinically by profuse scaling, histologically by a greatly thickened epidermis with increased mitotic activity and by the presence of immature nucleated cells in the horny layer and under the electron microscope by reduced production of intracellular filaments and granules seen within normal keratinization and biochemically by increased synthesis and degradation of nucleoproteins [4]. Psoriasis is associated with changes in blood biochemistry too.

\section{Aim}

1. To classify various types of psoriasis and find out various triggering factors in psoriasis.

2. To calculate various biochemical parameters in psoriasis correlate them clinically

\section{Material and Methods}

We selected fifty patients from the dermatology OPD. Prior approval of hospital ethics committee was taken and a written informed consent was taken from all the patients. All the patients were subjected to detailed history and clinical examination. Routine investigations and histopathological examination was performed in all the cases.

The following biochemical investigations were performed in all the patients - serum uric acid, serum calcium, serum albumin, serum globulin, serum bilirubin, serum creatinine, serum alkaline phosphatase, SGOT and SGPT. The biochemical tests were done before the initiation of the therapy and during the remission phase of the disease. 
The following patients were excluded from the study:

1. Patients having impaired renal functions or pre-existing renal disease.

2. Patients with acute uncontrolled bacterial, viral or fungal infection.

3. Patients on concomitant use of hepatotoxic or nephrotoxic drugs for any other long standing illness.

The psoriasis area and severity index (PASI) was recorded in all the patients.

\section{Results}

The data was compiled and the results were analyzed statistically using chi square test.

\section{Age Distribution}

Table I shows that maximum number of cases $(22 \%)$ were in

\begin{tabular}{|c|c|l|l|}
\hline Sr No & Age & $\begin{array}{c}\text { Number of } \\
\text { patients }\end{array}$ & $\begin{array}{c}\text { Percentage } \\
(\%)\end{array}$ \\
\hline 1 & $0-10$ & 2 & 4 \\
\hline 2 & $11-20$ & 6 & 12 \\
\hline 3 & $21-30$ & 9 & 18 \\
\hline 4 & $31-40$ & 10 & 20 \\
\hline 5 & $41-50$ & 8 & 16 \\
\hline 6 & $51-60$ & 11 & 22 \\
\hline 7 & $>60$ & 4 & 8 \\
\hline & Total & 50 & 100 \\
\hline
\end{tabular}

Table I. Age distribution of psoriasis.

Mean deviation - 2.694

Standard deviation -3.287

Coefficient of variability -8.54

Mean age $-38.46+3.287$ the age group of 51-60 years, followed by $20 \%$ in the age group of $31-40$ years, $18 \%$ in the age group $21-30$ years, $16 \%$ in the age group $41-50$ years, $16 \%$ in the age group $11-20$ years, $12 \%$ in the age group $0-10$ years and $8 \%$ of the cases were above 60 years of age. In our study, the mean deviation was 2.694 and the standard deviation was 3.287 . The coefficient of variability was 8.54 and the mean age of the patients was $38.46+3.287$.

\section{Incidence of Different Types of Psoriasis}

Table II shows that out of 50 cases of psoriasis, maximum incidence was of psoriasis vulgaris with 16 (32\%) cases, followed by $14(28 \%)$ patients of guttate psoriasis. There were $8(16 \%)$ patients of erythrodermic psoriasis, $6(12 \%)$ patients of generalized pustular psoriasis and $6(12 \%)$ patients of palmoplantar psoriasis.

\begin{tabular}{|c|c|l|l|}
\hline Sr No & Types of psoriasis & $\begin{array}{c}\text { Number of } \\
\text { cases }\end{array}$ & \% age \\
\hline 1 & Psoriasis vulgaris & 16 & 32 \\
\hline 2 & Guttate psoriasis & 14 & 28 \\
\hline 3 & Erythrodermic psoriasis & 8 & 16 \\
\hline 4 & $\begin{array}{c}\text { Generalized pustular } \\
\text { psoriasis }\end{array}$ & 6 & 12 \\
\hline 5 & Palmoplantar psoriasis & 6 & 12 \\
\hline & Total & 50 & 100 \\
\hline
\end{tabular}

Table II. Incidence of different types of psoriasis.

\section{Triggering Factors in Psoriasis}

Table III shows various triggering factors in psoriasis patients. The commonest triggering factor in psoriasis patients was stress seen in $24(48 \%)$ patients. Trauma as a triggering factor was

seen in $10(20 \%)$ patients, drug intake in $18(36 \%)$ patients, alcoholism in $16(32 \%)$ patients and sunlight as a triggering factor was seen in $3(6 \%)$ patients

\begin{tabular}{|c|c|l|l|}
\hline Sr No & $\begin{array}{c}\text { Triggering factors in } \\
\text { psoriatics }\end{array}$ & $\begin{array}{c}\text { Number of } \\
\text { cases }\end{array}$ & $\begin{array}{c}\text { Percentage } \\
(\%)\end{array}$ \\
\hline 1 & Stress & 24 & 48 \\
\hline 2 & Trauma & 10 & 20 \\
\hline 3 & Sore throat & 18 & 36 \\
\hline 4 & Alcoholism & 16 & 32 \\
\hline 5 & Drug intake & 18 & 36 \\
\hline 6 & Photo aggravation & 3 & 6 \\
\hline
\end{tabular}

Table III. Triggering factors in psoriasis. 


\section{Biochemical Parameters In Psoriasis}

Table IV shows that before the start of treatment, hypocalcaemia was seen in $5(10 \%)$ patients and at the end of treatment, serum calcium levels were normal in all the patients, which was found to be statistically significant $(\mathrm{p}>0.05)$. Hyperuricaemia was seen in $8(16 \%)$ patients before treatment and it was normal in all the patients after the treatment, which was found to be statistically significant ( $>0.05$ ). Hypoalbuminaemia was seen in $28(56 \%)$ patients before treatment and $2(4 \%)$ patients after treatment which was found to be statistically significant
( $p>0.05)$. Hyperglobulinaemia was seen in $22(44 \%)$ patients before treatment and $2(4 \%)$ patients after treatment which was also found to be statistically significant $(\mathrm{p}>0.05)$. Liver function tests were deranged in $5(10 \%)$ patients before treatment and 2 (4\%) patients after treatment which was found to be statistically significant $(\mathrm{p}>0.05)$. Serum creatinine was abnormal in 2 $(4 \%)$ patients before treatment and it was normal in all the patients after treatment, which was also found to be statistically significant $(\mathrm{p}>0.05)$.

\begin{tabular}{|c|c|c|c|c|c|c|}
\hline \multirow[t]{3}{*}{ SR No } & \multirow{3}{*}{$\begin{array}{l}\text { Biochemical } \\
\text { parameters }\end{array}$} & \multicolumn{4}{|c|}{ Time of making biochemical analysis } & \multirow[t]{3}{*}{ P value } \\
\hline & & \multicolumn{2}{|c|}{ At the start of treatment } & \multicolumn{2}{|c|}{ At the start of treatment } & \\
\hline & & Normal & Abnormal & Normal & Abnormal & \\
\hline 1 & Serum calcium & $45(90 \%)$ & $5(10 \%)$ & $50(100 \%)$ & 0 & $\mathrm{p}>0.05(\mathrm{~s})$ \\
\hline 2 & Serum uric acid & $42(84 \%)$ & $8(16 \%)$ & $50(100 \%)$ & 0 & $\mathrm{p}>0.05(\mathrm{~s})$ \\
\hline 3 & Serum albumin & $22(44 \%)$ & $28(56 \%)$ & $48(96 \%)$ & $2(4 \%)$ & $\mathrm{p}>0.05(\mathrm{~s})$ \\
\hline 4 & Serum globulin & $28(56 \%)$ & $22(44 \%)$ & $48(96 \%)$ & $2(4 \%)$ & $\mathrm{p}>0.05(\mathrm{~s})$ \\
\hline 5 & LFT's & $45(90 \%)$ & $5(10 \%)$ & $48(96 \%)$ & $2(4 \%)$ & $\mathrm{p}>0.05(\mathrm{~s})$ \\
\hline 6 & Serum Creatinine & $48(96 \%)$ & $2(4 \%)$ & $50(100 \%)$ & 0 & $\mathrm{p}>0.05(\mathrm{~s})$ \\
\hline
\end{tabular}

Table IV. Biochemical parameters before and after treatment.

\section{Discussion}

There were significant alterations in different biochemical values in patients before and after treatment [5]. With clinical improvement (Fig. 1 - 4), there was shift of biochemical parameters towards normal value. While analyzing the triggering factors, it was seen that mental stress was the most important triggering factor seen in $48 \%$ of patients. Psychological factors can trigger the onset or exacerbation of disease [6]. Some say that psoriasis is a psychosomatic disease and profound acute or chronic emotional stresses can induce or aggravate the course of disease. It is still unknown how psychic stress affects the first occurrence or exacerbation of psoriasis. The stress reaction in the patients is mediated by hypothalamic, pituitary adrenal relationship with immunologic effects.

In our study, the most common cause of stress was the death of a family member followed by monetary and matrimonial problems. The commonest factor for the onset of the disease is the environment in which a person has been living and working for a longer period of time and attitude of a person towards such environment.

The other commonest triggering factor was found to be drug intake, which was seen in $36 \%$ of patients. In our study, steroid withdrawal was the commonest triggering factor followed by use of beta-blockers. Sore throat was found to be a triggering factor in $36 \%$ of cases. ASO titres were positive in $10 \%$ of cases and were found to be positive in patients of guttate psoriasis only. Throat swab culture was found to be positive in $20 \%$ of cases and in all the cases, streptococcus haemolyticus was found to be the causative organism [7].

Alcoholism was found to be a triggering factor in $32 \%$ of cases. Alcohol intake should be discouraged in all the psoriatics. This is because there is a positive correlation between psoriasis and alcohol intake [8]. Moreover, alcohol induced liver problems may preclude the patients from receiving systemic therapy in future.

Trauma as a trigger was found in $22 \%$ of cases. Any form of trauma results in psoriasis appearing in the traumatized areas known as koebner's phenomenon [9]. Koebner's phenomenon occurs only at certain times in the lives of-the persons with psoriasis. Koebner effect can be induced by trauma at sites distant from existing lesions [10].

Regarding the seasonal variation, winter aggravation was seen in $52 \%$ cases, $6 \%$ patients had summer aggravation, $6 \%$ patients had spring aggravation and $4 \%$ had aggravation in the rainy season [11].

Decreased serum proteins occur in psoriasis. A decrease in albumin occurs when there is either impairment of albumin formation or excessive loss of albumin [12]. There are many causes of hypoalbuminaemia. It is because of loss of albumin through skin in psoriatic patients. Increased endogenous catabolism of endogenous albumin is the real cause of hypoalbuminaemia. Another cause of hypoalbuminaemia is because of increased albumin clearance from involved psoriatic skin due to an increased lymphatic return, which might serve as a compensatory mechanism.

Hyperuricaemia is seen in psoriasis. In ours study, $16 \%$ of patients had increased serum uric acid levels. Increased purine metabolism occurs ill' psoriasis because of increased epidermal cell turnover [13]. Various studies have failed to demonstrate any direct connection between the frequency of hyperuricaemia and the extent of psoriatic skin involvemen [14]. 


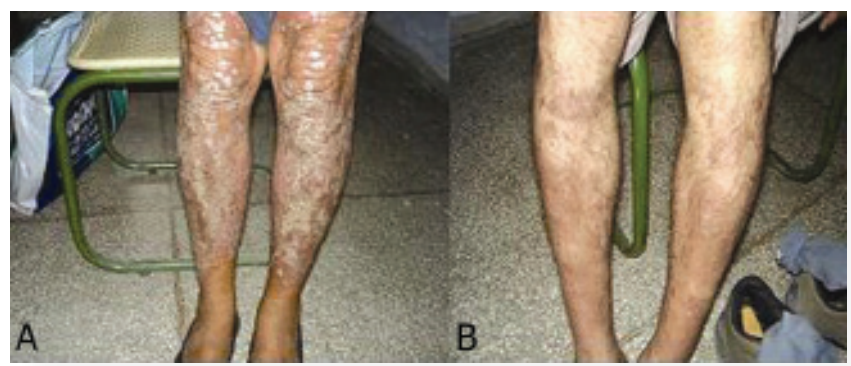

Figure 1A and B. Patient on PUVA therapy before and after treatment.

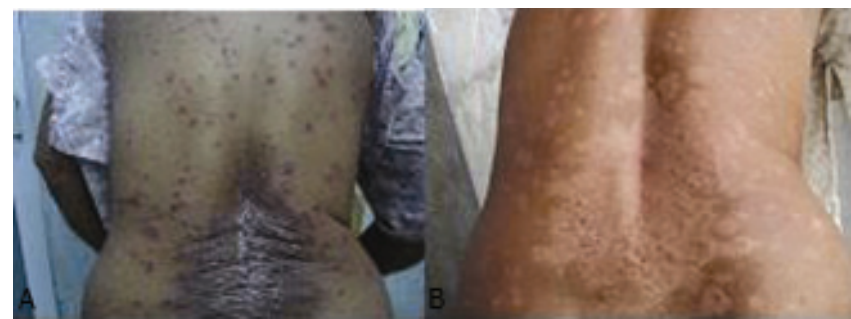

Figure $3 \mathrm{~A}$ and $\mathrm{B}$. Patient on acitretin before and after treatment.

The fact that the incidence of hyperuricaemia in psoriatic subjects is unchanged even after clearing of psoriatic lesions by various medications shows that psoriatic skin changes are not responsible for psoriatic hyperuricaemia. Genetic predisposition could be a reasonable explanation for hyperuricaemia in psoriasis patients.

Thus,the issue is still fraught with speculations. Total serum calcium alterations in psoriasis patients have been varyingly reported, showing thereby a decreased or a normal level [15]. Calcium depletion from horny layer may play a role in the formation of psoriatic skin lesions. In our study, hypocalcaemia was seen in $10 \%$ of patients and normal calcium levels in $90 \%$ of patients. The significance of total serum calcium in psoriasis is yet to be established. ASO titres were positive in $10 \%$ cases in our study. Also, it was seen that ASO titres were positive in patierits of guttate psoriasis only. Throat swab culture was positive in $20 \%$ cases arid in all the cases streptococcus haemolyticus was found to be the causative-organism. Significant improvement of PAS I score was seen in all the patients before and after treatment [16]. A 75\% reduction in PASI score (PAS 75) used to be the current bench mark of primary end point for most clinical trials of psoriasis. But, many consider this end point to be too stringent as it places potentially useful therapies at risk of failing to demonstrate efficacy. Therefore, a $50 \%$ reduction in the PASI score (PASI 50) represents a meaningful change in a persons life and thus is a better primary endpoint $[17,18]$. In our study, there was $75 \%$ reduction in PASI score in $52 \%$ cases and $50 \%$ reduction in PASI score in $48 \%$ cases.

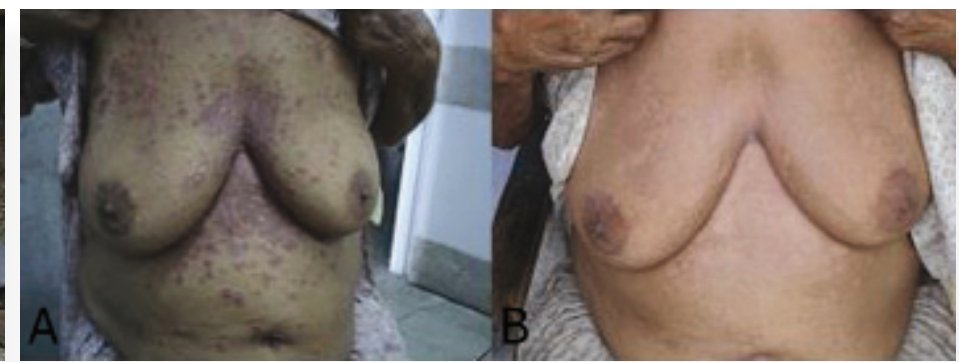

Figure 2A and B. Patient on methotrexate before and after treatment.

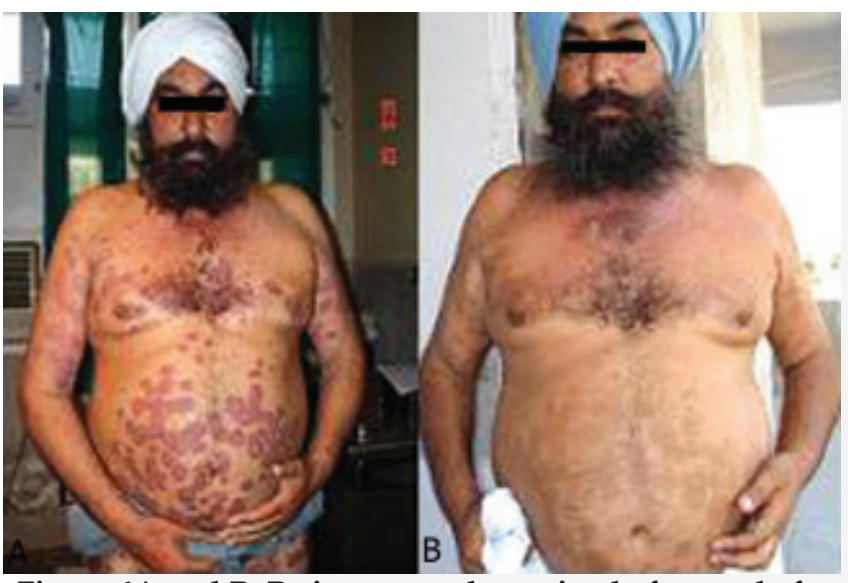

Figure 4A and B. Patient on cyclosporine before and after treatment.

\section{Conclussion}

There were significant alterations seen in the biochemistry of the patients before and after treatment. After treatment, clinical improvement along with shift of the deranged parameters towards normal values was seen. Significant improvement in PASI was also seen before and after treatment.

Biochemical changes are important not only in understanding the pathogenesis of psoriasis but also act as a diagnostic and prognostic parameter in psoriasis in acute exacerbation [19]. In addition, the recognition of triggering factors in psoriasis not only helps in the prevention of disease exacerbation but also its better management.

\section{REFERENCES}

1. Farber EM, Nall ML. The natural history of psoriasis in 5600 patients. Dermatologica. 1974;148:1-18.

2. Barker IN. The pathophysiology of psoriasis. Lancet. 1991;338:222-30.

3. Bhalerao J, Bowcock AM. The genetics of psoriasis: a complex disorder of the skin and immune system. Hum Mol Genet. 1998; 7:1537-45.

4. Natson W, Comn HM, Farber EM. The genetics of psoriasis Arch Dermatol. 1992;5:197.

5. Ragaz A, Ackerman AB. Evolution, maturation and regression of lesions of psoriasis. am J Dermatopathol. 1979;3:199-214. 
6. Fortune DG, Main CJ, O'Sullivan TM, Griffiths CE. Quality of life in patients with psoriasis: The contribution of clinical variables and psoriasis specific stress. Br J Dermatol. 1997;137:755-60.

7. Whyte HJ, Baughman RD. acute guttate psoriasis and streptococcal infection. Arch Dermatol. 1964;89:350-56.

8. Poikilolainew K, Karkkainem P. Alcohol intake: A risk factor for psoriasis in young and middle aged man. BMJ. 1990;300:780-3.

9. Reinertson R. vascular trauma and pathogenesis of koebner reaction in psoriasis. J Invest Derm. 1968;30;283.

10. Rosenberg EW, Noah PW. The koebner phenomenon and the microbial basis of psoriasis. J Am Acad Dermatol. 1988;18:151-8.

11. Kavli G, Førde OH, Arnesen E, Stenvold SE. Psoriasis: Familial disposition and environmental factors. Br Med J. 1985;291:9991000 .

12. Tickner A, Mier PD. Serum cholestrol, uric acid and proteins in psoriasis. Br J Dermatol. 1990;72:131-7.

13. Caraway WT. Determination of uric acid in blood in psoriatics. Am J Clin Pathol. 1995;25:840-3.
14. Bauman RR, Julson OP. Hyperuricaemia and psoriasis. J Invest Dermatol. 1991;36:105-7.

15. Clark EP, Collip JB. Determination of serum calcium in psoriatics. J Biochemistry. 1985;63:1961-3.

16. Feldman SR, Fleischer AB. The self administered psoriasis area and severity index is valid and reliable. J Invest Dermatol. 1996;106:183-6.

17. Carlin CS, Feldman SR, Krueger JG, Menter A, Krueger GG. A $50 \%$ reduction in the psoriasis area and severity index is a clinically significant end point in the assessment of psoriasis. J Am Acad Dermatol. 2004;50:859-66.

18. Langley RG, Ellis EN. Evaluating psoriasis with psoriasis area and severity index (P AS I). J Am Acad Dermatol. 2004;51:563-9. 19. Shelly WB, Arthur PP. Biochemical and physiological clues to the nature of psoriasis. Arch Derm. 1998;321:78-82. permits unrestricted use, distribution, and reproduction in any medium, provided the original author and source are credited. 